INFLAMMATION

\title{
Growth, phenotype, and function of human intestinal mast cells are tightly regulated by transforming growth factor $\beta 1$
}

\author{
T Gebhardt, A Lorentz, F Detmer, C Trautwein, H Bektas, M P Manns, S C Bischoff
}

Gut 2005;54:928-934. doi: 10.1136/gut.2004.054650

Background and aims: Transforming growth factor $\beta 1$ (TGF- $\beta 1$ ) is expressed in the healthy human intestine and controls mucosal immune responses and inflammation by regulating the function of lymphocytes, macrophages, dendritic cells, and eosinophils. Here, we asked whether human intestinal mast cells (MC) might also be subject to immunoregulation by TGF- $\beta 1$.

See end of article for authors' affiliations

Methods: MC were isolated from the intestinal mucosa, purified, and cultured in vitro in the presence of stem cell factor (SCF) with or without TGF- $\beta 1$. Growth characteristics, phenotype, and immunological mediator release of $M C$ were analysed by reverse transcription-polymerase chain reaction, flow cyłometry, immunocytochemistry, western blot, and different immunoassays, respectively.

Correspondence to
Prof S C Bischoff,

Department of Clinical

Nutrition and Prevention

(140b), University of

Hohenheim, D-70593

Stuttgart, Germany;

bischoff.stephan@

uni-hohenheim.de

Revised version received

23 December 2004

Accepted for publication

15 February 2005

Results: TGF- $\beta 1$ dose dependently (ED50 $\approx 0.1 \mathrm{ng} / \mathrm{ml}$ ) inhibited SCF dependent growth of human intestinal MC by both enhancing apoptosis and decreasing proliferation. In parallel, TGF- $\beta 1$ increased the percentage of connective tissue-type $M C$ expressing tryptase and chymase while downregulating expression of the receptors for lgE and SCF. Furthermore, TGF- $\beta 1$ dramatically changed the profile of mediators released by MC following lgE receptor crosslinking. Release of histamine, cysteinyl-leukotrienes, and tumour necrosis factor $\alpha$ was strongly reduced whereas prostaglandin D2 generation and cyclooxygenase 1 and 2 expression were upregulated by TGF- $\beta 1$.

Conclusions: Our data indicate that TGF- $\beta 1$ acts as a novel potent inhibitor and modulator of human intestinal $M C$ effector functions. The change in $M C$ mediator release profile and protease expression induced by TGF- $\beta 1$ might be of relevance for the control of MC associated disorders of the intestine such as allergic reactions, Crohn's disease, irritable bowel syndrome, and parasitic infection.

$\mathrm{T}$ ransforming growth factor $\beta 1$ (TGF- $\beta 1$ ) is an immunoregulatory cytokine constitutively expressed in the human gut by various tissue cells, such as epithelial cells and different lamina propria cells. ${ }^{1}$ It acts as an antiinflammatory cytokine by modulating $\mathrm{T}$ cell and dendritic cell function (for example, by induction of regulatory $\mathrm{T}$ cells and IgA production in plasma cells, but also by controlling inflammatory effector cells such as macrophages and eosinophils)..$^{2-4}$ On the other hand, TGF- $\beta 1$ is involved in regulating tissue repair processes by affecting epithelial cells, fibroblasts, and by inducing extracellular matrix production. This dual function of TGF- $\beta 1$ is confirmed by in vivo experiments using genetically modified animal models. TGF- $\beta 1$ and TGF- $\beta$ receptor II (TGF-RII) gene knockout mice develop a lethal multifocal inflammation involving several organs, including the intestine, ${ }^{67}$ whereas mice over expressing TGF- $\beta 1$ in different organs develop tissue fibrosis. ${ }^{8}{ }^{9}$

Mast cells (MC) are known to be involved in both processes. They act as inflammatory effector cells releasing mediators such as histamine, eicosanoids, and tumour necrosis factor $\alpha$ (TNF- $\alpha$ ) in the course of inflammatory conditions (for example, allergic reactions, parasitic infections, and inflammatory bowel disease) and, as shown recently, in the irritable bowel syndrome. ${ }^{10-12}$ Secondly, MC accumulate at sites of wound healing and tissue fibrosis. ${ }^{10^{11} 13}$ In the normal human gut they are primarily located in the mucosa where they represent approximately $2-3 \%$ of all lamina propria cells. At sites of inflammation or fibrosis, their number may be substantially increased and their distribution may expand to other layers of the bowel wall such as the epithelial layer or the muscularis propria. ${ }^{11}{ }^{13}$

Regulation of human MC growth and mediator release is dependent on cytokines such as stem cell factor (SCF), interleukin (IL)-3, -4, and others, which either alone or in combination promote MC growth and maturation, and enhance mediator release in response to IgE dependent and IgE independent triggering agents. ${ }^{10}{ }^{14-18}$ However, our knowledge of endogenous inhibitors of human MC function is poor. In the murine system, TGF- $\beta 1$ has been proposed as an inhibitor of MC growth. ${ }^{19-22}$ Whether TGF- $\beta 1$ also regulates $\mathrm{MC}$ mediator release is unclear as experiments in mice yielded conflicting results. ${ }^{21-24}$ In humans, no data are available as yet but TGF- $\beta 1$ may also affect human MC functions, as reported by Olsson et al who found that TGF- $\beta 1$ has chemotactic and growth inhibitory effects in the immature human leukaemic mast cell line HMC-1 and in human cord blood derived MC. ${ }^{25}$ The reason for the inconsistent data about TGF- $\beta$ l effects on MC may be that different types of MC derived from different species, from different body sites, and of different maturity grades were used in previous experiments. Here we examined for the first time the effects of TGF- $\beta 1$ on in vivo maturated human MC isolated from intestinal tissue and purified to homogeneity. The aim of the study was to define the function of TGF- $\beta 1$ in regulating $\mathrm{MC}$ growth, protease, and surface receptor expression, and mediator release.

Abbreviations: cys-LT, cysteinyl-leukotrienes; COX, cyclooxygenase cPLA2, cytosolic phospholipase A2; IgER, high affinity lgE receptor; IL, interleukin; mAb, monoclonal antibody; MC, mast cell; PGD2, prostaglandin D2; PGDS, haematopoietic prostaglandin synthase; RT-PCR, reverse transcription-polymerase chain reaction; SCF, stem cell factor; SDS, sodium dodecyl sulphate; TGF- $\beta$, transforming growth factor $\beta$; TGF-R, TGF- $\beta$ receptor; TNF- $\alpha$, tumour necrosis factor $\alpha$; TUNEL, terminal deoxynucleotidyl transferase mediated dUTP nick end labelling 


\section{METHODS \\ Isolation, purification, and culture of human intestinal MC}

MC were isolated from surgery tissue specimens (small and large intestine, bowel resection because of cancer, macroscopically normal intestinal tissue) using a four step enzymatic dispersion method, and subsequently purified by positive selection of $c$-kit expressing cells using magnetic cell separation (MACS system, Miltenyi Biotech, BergischGladbach, Germany), as described previously. ${ }^{15}{ }^{16} \mathrm{MC}$ (purity $60 \pm 35 \%)$ were cultured at a density of $1-2 \times 10^{5}$ cells $/ \mathrm{ml}$ in medium supplemented with recombinant human SCF ( $50 \mathrm{ng} / \mathrm{ml}$; Amgen, Thousand Oaks, California, USA), IL-4 ( 2 ng/ml; Novartis, Vienna, Austria), activated TGF- $\beta 1$ ( 5 ng/ ml; PeproTech, Rocky Hill, New Jersey, USA), or with a combination of these cytokines. To block TGF- $\beta 1$ bioactivity, a neutralising anti-TGF- $\beta 1$ monoclonal antibody (mAb) (clone 9016.2; R\&D Systems, Minneapolis, Minnesota, USA) was added to the culture medium every fourth day. During the culture period, MC purity increased independent of the cytokines added from $60 \pm 35 \%$ to $98 \pm 2 \%$, with fibroblasts remaining the only contaminating cells. MC purity and recovery (expressed as per cent of MC numbers at the start of the culture) were determined by cell counting using trypan blue staining (Sigma Chemicals, St Louis, Missouri, USA) and differentiation of cells on cytospin smears stained with May-Grünwald/Giemsa (Merck, Darmstadt, Germany). To confirm the MC recovery data, histamine content per well was measured by RIA (Coulter-Immunotech, Krefeld, Germany) after washing the cells and subsequent cell lysis.

\section{Mediator release assays}

Following culture, MC were washed and seeded at a density of 0.5 to $1 \times 10^{5}$ cells $/ \mathrm{ml}$ in culture medium without antibiotics or cytokines. MC were stimulated by IgE receptor (IgER) crosslinking using the mAb29C6 (100 ng/ml, 90 or 360 minutes; Hoffmann-La Roche, Nutley, New Jersey, USA). Histamine release into supernatants was measured by RIA and expressed as specific histamine release according to the following formula:

(histamine released after IgER crosslinking-histamine released spontaneously in response to buffer control)/total cellular histamine content as determined after cell lysis.

Cysteinyl-leukotrienes (cys-LT) were measured by RIA as described previously. ${ }^{15}$ Prostaglandin D2 (PGD2) was measured by PGD2 methoxime EIA (Cayman Chemical Company, Ann Arbor, Michigan, USA) and TNF- $\alpha$ was measured by ultrasensitive ELISA (BioSource Europe, Nivelles, Belgium). Release of cys-LT, PGD2, and TNF- $\alpha$ into the supernatant was expressed as specific mediator release obtained by subtraction of mediator release in response to buffer control.

\section{RNA isolation and reverse transcriptase-polymerase chain reaction (RT-PCR)}

Total RNA was prepared using the RNeasy Mini Kit (Qiagen, Hilden, Germany) and RT-PCR was carried out as described previously. ${ }^{16}{ }^{18}$ The following primer sequences were used: TGF-RI: 5' -AAT TCC TCG AGA TAG GCC GT-3', 5' -TGC GGT TGT GGC AGA TAT AG-3'; TGF-RII: 5'-AGG GAC CTC AAG AGC TCC AAT AT-3', 5' -CAC TGC ATT ACA GCG AGA TGA CA-3'; $\beta$-glycan: 5'-CCT GTC ATT CCC AGC ATA CAA CT-3', 5'-ATC ACC TGA CAC CAG ATC TTC ATA-3'; endoglin: 5'TGT CTC ACT TCA TGC CTC CAG CT-3', 5'-AGG CTG TCC ATG TTG AGG CAG T-3'26; cytosolic phospholipase A2 (CPLA2): 5'-ATT CTG GAT TGT GCT ACC TAC-3', 5'-AAC CAG AAA CGC CCA AAA CTC-3' $)^{27}$; cyclooxygenase (COX)-1: 5'-TGC CCA GCT CCT GGC CCG CCG CTT-3', 5'-GTG CAT CAA CAC AGG CGC CTC TTC-3'; COX-2: 5'-TTC AAA TGA
GAT TGT GGG AAA ATT GCT-3', 5'-AGA TCA TCT CTG CCT GAG TAT CTT-3'28; haematopoietic prostaglandin synthase (PGDS): 5'-CTT CAC CAG AGC CTA GCA AT-3', 5' -GGA TTA TCT GGC AGG CTG AT- $3^{\prime}{ }^{29}$; and GAPDH: $5^{\prime}$-ACC ACA GTC CAT GCC ATC AC-3'; 5'-TCC ACC ACC CTG TTG CTG TA-3' (all synthesised by Life Technologies, Eggenstein, Germany).

\section{Immunocytochemistry}

Immunocytochemistry was performed using mAbs against human tryptase (clone G3 $(0.24 \mu \mathrm{g} / \mathrm{ml})$, human chymase $(0.24 \mu \mathrm{g} / \mathrm{ml})$, both from Chemikon, Temecula, California, USA), the human nuclear cell proliferation associated antigen Ki-67 (clone MIB-1, dilution 1:50; Dianova, Hamburg, Germany), and appropriate isotype control mAbs (mouse IgGl; Southern Biotechnology, Birmingham, Alabama, USA) as primary antibodies (overnight incubation at $4^{\circ} \mathrm{C}$ ) and the streptavidin-biotin detection system (Histostain-Plus kit; Zymed, San Francisco, California, USA). Percentage of apoptotic MC was assessed using the terminal deoxynucleotidyl transferase mediated dUTP nick end labelling (TUNEL) in situ cell death detection assay for immunocytochemistry (Boehringer Mannheim, Mannheim, Germany) according to the manufacturer's instructions.

\section{Flow cytometry}

For each condition, $2.5-5 \times 10^{4}$ MC (purity $98 \pm 2 \%$ ) were washed (400 g, five minutes) and suspended in $100 \mu \mathrm{l}$ phosphate buffered saline supplemented with $0.1 \%$ bovine serum albumin, $0.1 \%$ sodium acid, $250 \mu \mathrm{g} / \mathrm{ml}$ rabbit IgG, and mAbs directed against TGF-RII $(2.5 \mu \mathrm{g} / \mathrm{ml}$; R\&D Systems $)$, c-kit (clone YB5.B8, $2.5 \mu \mathrm{g} / \mathrm{ml}$; Pharmingen), IgER $\alpha$-chain (clone 29C6, $2.5 \mu \mathrm{g} / \mathrm{ml}$ ), or the appropriate isotype control
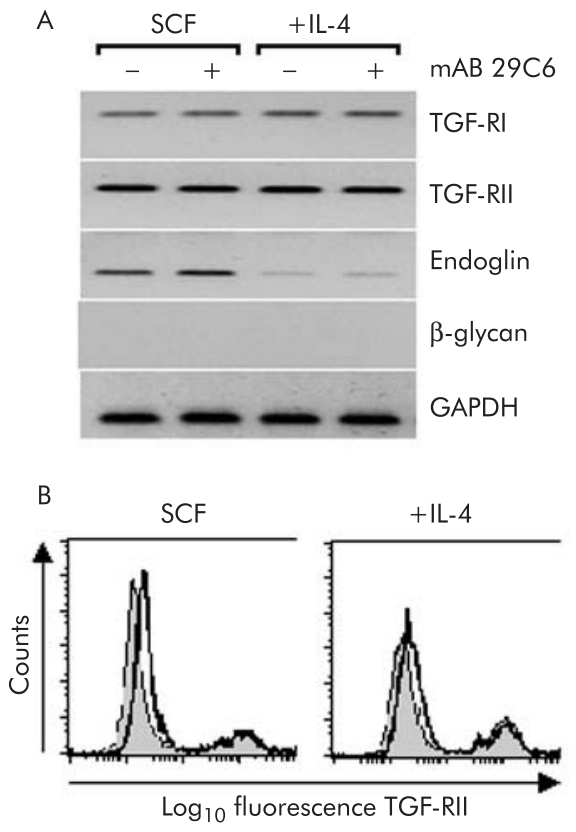

Figure 1 Expression of transforming growth factor $\beta$ receptor molecules (TGF-RI, TGF-RII) in human intestinal mast cells (MC). (A) mRNAs encoding for GAPDH (452 bp), TGF-RI (224 bp), TGF-RII (261 bp), endoglin (364 bp), and $\beta$-glycan (378 bp) detected by reverse transcription-polymerase chain reaction in MC following culture for 14 days in the presence of stem cell factor (SCF $25 \mathrm{ng} / \mathrm{ml}$ ) or SCF and interleukin 4 (IL-4 $2 \mathrm{ng} / \mathrm{ml})$, and subsequent challenge for 90 minutes with mAb29C6 (+) or buffer control $(-)$. One of four representative experiments is shown (98 (2)\% MC purity). (B) Surface expression of TGF-RIl protein following culture of MC with SCF, or SCF and IL-4; matched isotype control staining in grey (one of three experiments). 

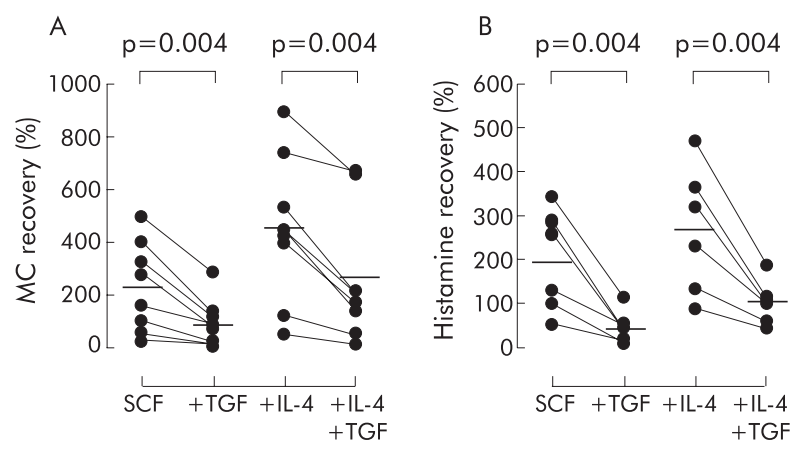

Figure 2 Transforming growth factor $\beta 1$ (TGF- $\beta 1$ ) inhibited mast cell (MC) growth in vitro. Purified MC were cultured for 14-21 days in medium supplemented with stem cell factor (SCF $25 \mathrm{ng} / \mathrm{ml}$ ), with SCF and TGF- $\beta 1(5 \mathrm{ng} / \mathrm{ml})$, with SCF and interleukin $4(\mathrm{IL}-42 \mathrm{ng} / \mathrm{ml})$, or with all three cytokines. (A) $M C$ recovery (expressed in per cent; $M C$ number at the start of the culture was set $100 \%$ ) after culture (symbols indicate individual data performed in duplicate; horizontal bars indicate means $(n=8)$ ). (B) Histamine recovery after culture (cellular histamine content was measured after cell lysis; histamine content at culture start was set at $100 \% ; n=6$ ). Data derived from the same MC preparations (with or without TGF- $\beta 1$ ) are connected.

mAbs (goat IgG (Dianova) and mouse IgGl (R\&D Systems)). After incubation for 30 minutes at $4^{\circ} \mathrm{C}$, cells were washed twice and stained for 30 minutes at $4^{\circ} \mathrm{C}$ with FITC conjugated secondary antibodies (Southern Biotechnology). Apoptotic cells were visualised using FITC conjugated annexin V/ propidium iodide double staining (R\&D Systems) according to the manufacturer's instructions.
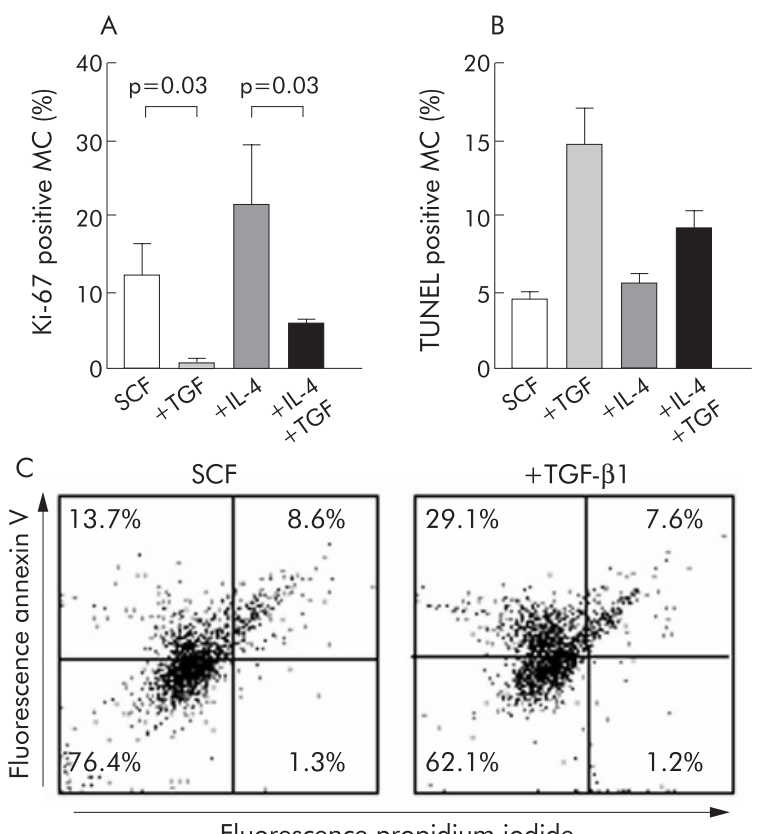

Fluorescence propidium iodide

Figure 3 Transforming growth factor $\beta 1$ (TGF- $\beta 1$ ) increased mast cell (MC) apoptosis and reduced $M C$ proliferation. Experimental conditions are as described in fig 2. (A) MC proliferation assessed by immunocytochemistry as percentage of $M C$ expressing the human nuclear cell proliferation associated antigen Ki-67 after culture (means (SD), $n=5$ ). (B) MC apoptosis determined by terminal deoxynucleotidyl transferase mediated dUTP nick end labelling (TUNEL) assay in MC cytospins after culture (means (SD), $n=3$ ). (C) Surface binding of annexin $V$ during the early course of apoptotic cell death was measured by flow cytometry following culture of MC with stem cell factor (SCF), or SCF and TGF- $\beta 1$ (one of three representative experiments). IL-4, interleukin 4 .

\section{Western blot}

To obtain whole cell extracts, $0.5 \times 10^{6}$ MCs were lysed in extraction buffer containing $25 \mathrm{mM}$ Tris $\mathrm{HCl}, \mathrm{pH} 7.5,0.5 \mathrm{mM}$ EDTA, $0.5 \mathrm{mM}$ EGTA, $0.05 \%$ Triton X-100, $10 \mathrm{mM}$ $\beta$-mercaptoethanol, supplemented with the protease inhibitor cocktail Complete Mini (Roche Diagnostics, Germany). Cell extracts (10-20 $\mu \mathrm{g}$ protein each) were separated on a $12 \%$ sodium dodecyl sulphate (SDS) polyacrylamide gel and blotted onto a nitrocellulose membrane (Schleicher and Schuell, Einbeck, Germany) in $0.1 \%$ SDS, $20 \%$ methanol, $400 \mathrm{mmol} / \mathrm{l}$ glycine, $50 \mathrm{mmol} / \mathrm{l}$ Tris HCL, pH 8.3, at $4^{\circ} \mathrm{C}$ for four hours at $40 \mathrm{~V}$ by electroblotting using the Trans-Blot Cell system (Bio-Rad Laboratories, Munich, Germany). Membranes were blocked with 5\% skimmed milk in phosphate buffered saline containing $0.1 \%$ Tween overnight. Membranes were probed with anti-COX1, anti-COX2, antiPGDS (all Cayman Chemicals), anti-cPLA2 (Upstate Biotech, Lake Placid, New York, USA), and anti-actin Ab (Santa Cruz, California, USA). The antigen-antibody complexes were visualised using an electrochemiluminescence detection system, as described by the manufacturer (NEN Life science, Boston, Massachusetts, USA). To confirm that equal amounts of protein were used for the western blots of COX-1 and 2, membranes were stripped (Restore western blot stripping buffer; Perbio, Rockford, Illinois, USA) for 30 minutes at $37^{\circ} \mathrm{C}$ and probed again with the anti-actin $\mathrm{Ab}$.

\section{Statistics}

All data are expressed as mean (SD) if not indicated otherwise. Significance of differences was assessed using the Wilcoxon signed rank test. A p value of $<0.05$ was considered statistically significant.

\section{RESULTS}

Expression of TGF- $\beta$ receptors in human intestinal MC Using RT-PCR, we detected expression of transcripts for TGF-RI, TGF-RII, and the accessory TGF-R endoglin in freshly purified (purity $>95 \%$, not shown) as well as in cultured MC (fig lA). TGF-RII protein expression was confirmed by flow cytometry (fig 1B). IL-4 supplementation to the culture medium decreased the amount of endoglin mRNA whereas IgER crosslinking induced by incubation with mAb29C6 for 90 minutes did not affect expression of any TGF-R mRNAs.

\section{TGF- $\beta 1$ inhibits growth of cultured human intestinal $M C$}

Addition of TGF- $\beta 1$ to the culture medium caused a marked decrease in MC recovery from 228.9 (159.4)\% to $88.8(88.4) \%$ in the presence of SCF, and from $449.3(260.5) \%$ to 264.9 (241.8)\% in the presence of SCF and IL-4 (fig 2A). Histamine recovery was reduced in a similar fashion (fig $2 \mathrm{~B}$ ).

TGF- $\beta 1$ added to the culture medium caused a marked reduction in MC proliferation, as assessed by anti-Ki-67 staining. In accordance with our previous studies, ${ }^{16}{ }^{18}$ we found $12.4(9) \% \mathrm{Ki}-67^{+} \mathrm{MC}$ in the presence of SCF and 21.3 (18.0)\% in the presence of SCF and IL-4. TGF- $\beta 1$ almost abolished MC proliferation when added to cultures containing SCF ( $1.0(0.9) \% \mathrm{Ki}-67^{+}$cells) or SCF and IL-4 (6.0 (1.4)\%) (fig 3A). Light microscopy analysis of May-Grünwald/Giemsa stained cytospin preparations revealed an increase in MC displaying morphological alterations associated with apoptosis (for example, decreased cell size, increased cell density, nuclear condensation) when cells were cultured in the presence of TGF- $\beta 1$ (not shown). TUNEL assay experiments performed with cytospin preparations, as well as annexin $\mathrm{V}$ and propidium iodide double staining for flow cytometry in order to detect apoptotic MC, confirmed this observation (fig 3B, C). 

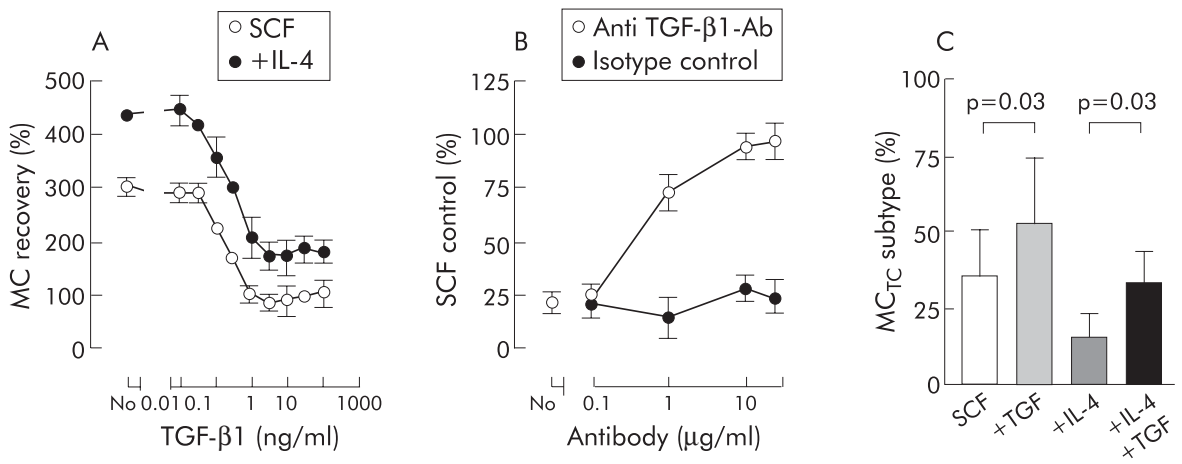

Figure 4 Characteristics of transforming growth factor $\beta 1$ (TGF- $\beta 1$ ) effects on mast cell (MC) growth and phenotype. MC were cultured for 14-21 days as in fig 2, except in (B). (A) Dose dependency of TGF- $\beta 1$ mediated growth inhibition in MC (means (SD), one of two experiments shown). (B) Effect of a neutralising anti-TGF- $\beta 1$ monoclonal antibody (Ab) added every four days at different concentrations to the culture medium supplemented with $25 \mathrm{ng} / \mathrm{ml}$ stem cell factor (SCF) and $1 \mathrm{ng} / \mathrm{ml} \mathrm{TGF}-\beta 1$. MC recovery following culture with SCF alone was set at $100 \%$. The inhibitory effect of TGF- $\beta 1$ (most left circle, $24 \%$ MC recovery) was abolished by anti-TGF- $\beta 1$ antibody at $\geqslant 10 \mu \mathrm{g} / \mathrm{ml}$ (means (SD), $\mathrm{n}=3$ ). (C) Detection of $M C$ proteases by immunocytochemistry revealed an enhanced proportion of $M C$ expressing both tryptase and chymase (MC TC subtype) after culture with additional TGF- $\beta 1$ (means (SD); $n=5$ ). IL-4, interleukin 4 .

The growth inhibitory effect of TGF- $\beta 1$ appeared in a concentration dependent fashion, with maximal inhibition at approximately $3 \mathrm{ng} / \mathrm{ml}$ and an $\mathrm{ED}_{50}$ of approximately $0.3 \mathrm{ng} / \mathrm{ml}(\mathrm{n}=2)$ ( fig $4 \mathrm{~A})$. Possible toxic effects of exogenous TGF- $\beta 1$ were largely excluded using an anti-TGF- $\beta 1$ mAb at different concentrations that abolished the inhibitory effect of TGF- $\beta 1$ on MC growth (fig 4B). The observation that maximal effective concentrations of the anti-TGF- $\beta 1 \mathrm{mAb}$
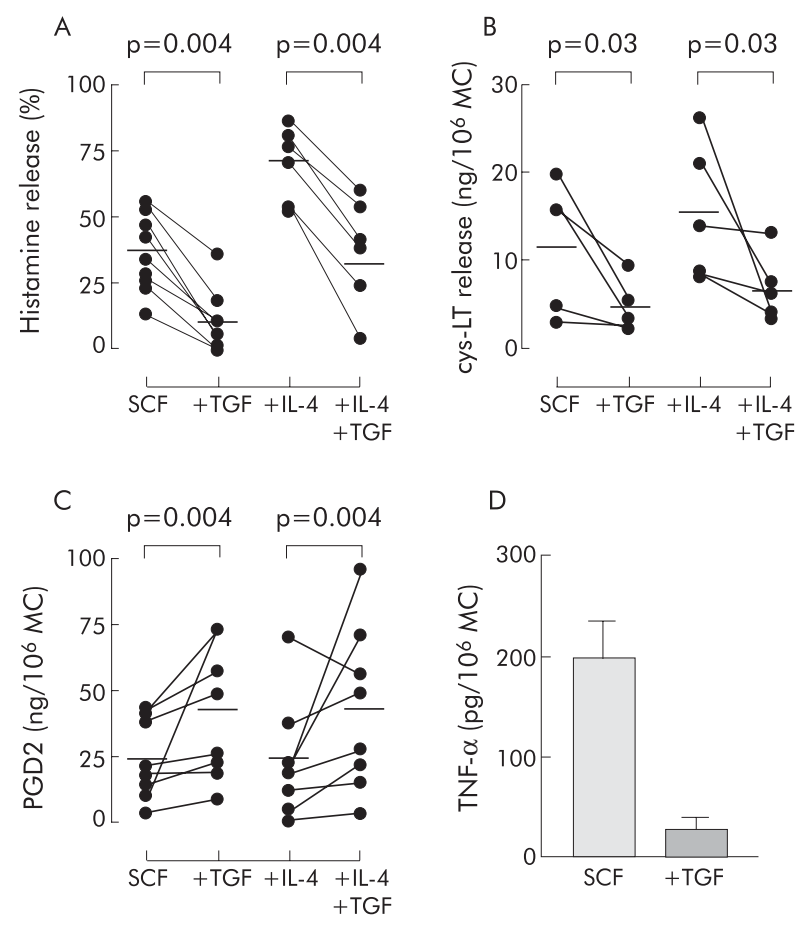

Figure 5 Transforming growth factor $\beta 1$ (TGF- $\beta 1$ ) dependent modulation of the mediator release profile in purified human intestinal mast cells (MC). After culture for 14 days with or without TGF- $\beta 1$ (for other culture conditions, see fig 2), $M C$ were washed and challenged with $\mathrm{mAb} 29 \mathrm{C} 6$ at $100 \mathrm{ng} / \mathrm{ml}$ for 90 minutes (A-C) or 360 minutes (D) to induce high affinity $\operatorname{lgE}$ receptor (lgER) crosslinking. Specific release of histamine $(A, n=8)$, cysteinyl-leukotrienes (cys-LT) $(B, n=5)$, prostaglandin D2 (PGD2) (C, n=8), and tumour necrosis factor $\alpha$ (TNF$\alpha)(D, n=3)$ is shown. Each symbol in $A-C$ represents one separate experiment performed in duplicate. SCF, stem cell factor; IL-4, interleukin 4. were not able to further augment MC recovery compared with SCF control conditions indicated that no endogenous TGF- $\beta 1$, either MC or serum derived, accounted for the effects we observed.

\section{TGF- $\beta 1$ increases the frequency of chymase expressing $M C$}

Two human MC subtypes have been defined according to their protease content: the tryptase positive, chymase negative $\mathrm{MC}\left(\mathrm{MC}_{\mathrm{T}}\right)$ and the tryptase and chymase double positive $\mathrm{MC}\left(\mathrm{MC}_{\mathrm{TC}}\right){ }^{10}{ }^{30} \mathrm{We}$ analysed these subtypes by immunocytochemistry using antibodies directed against the two proteases after culture of the MC with different cytokines $(n=5)$. Independent of the cytokines added to the culture medium, virtually all MC expressed tryptase. Confirming previous data, chymase expression was downregulated by IL-4 from 35.8 (20.9)\% of $\mathrm{MC}$ expressing the $\mathrm{MC}_{\mathrm{TC}}$ phenotype in the presence of SCF to $16.3(7.7) \% \mathrm{MC}_{\mathrm{TC}}$ in the presence of SCF and IL-4. ${ }^{16}$ However, TGF- $\beta 1$ significantly increased the proportion of chymase positive MC to 52.5 $(21.6) \%$ in the presence of SCF, and to $33.3(10.9) \%$ in the presence of SCF and IL-4, respectively (fig 4C).

\section{TGF- $\beta 1$ changes the mediator release profile in human intestinal $M C$}

TGF- $\beta 1$ not only affected MC growth but also mediator release induced by mAb29C6, causing IgER crosslinking. When added to the culture medium, TGF- $\beta 1$ decreased specific histamine release from 37.2 (15.1)\% to 10.6 (11.9)\% when MC were cultured with SCF and from 70.5 (16.0)\% to 33.3 (20.7)\% when MC were cultured with SCF and IL-4 (fig 5A). Similar results were obtained with respect to cys-LT and TNF- $\alpha$ production that was dramatically decreased in MC cultured with TGF- $\beta 1$ (fig 5B, D). In contrast, TGF- $\beta 1$ significantly increased PGD2 production from 23.3 (15.0) to 40.9 (25.5) ng/10 ${ }^{6} \mathrm{MC}$ (SCF) and from 23.1 (21.4) to 42.0 (31.1) $\mathrm{ng} / 10^{6} \mathrm{MC}$ (SCF and IL-4, fig 5C).

\section{TGF- $\beta 1$ reduces expression of receptors for IgE and SCF in human intestinal MC}

We also studied expression of receptors involved in MC regulation, such as $c$-kit and IgER, in MC cultured with and without TGF- $\beta 1$. As shown in fig 6, TGF- $\beta 1$ strongly downregulated expression of the SCF receptor c-kit $(\mathrm{n}=3)$. Furthermore, TGF- $\beta 1$ slightly reduced expression of the $\alpha$ chain of the high affinity IgER (fig 6). 


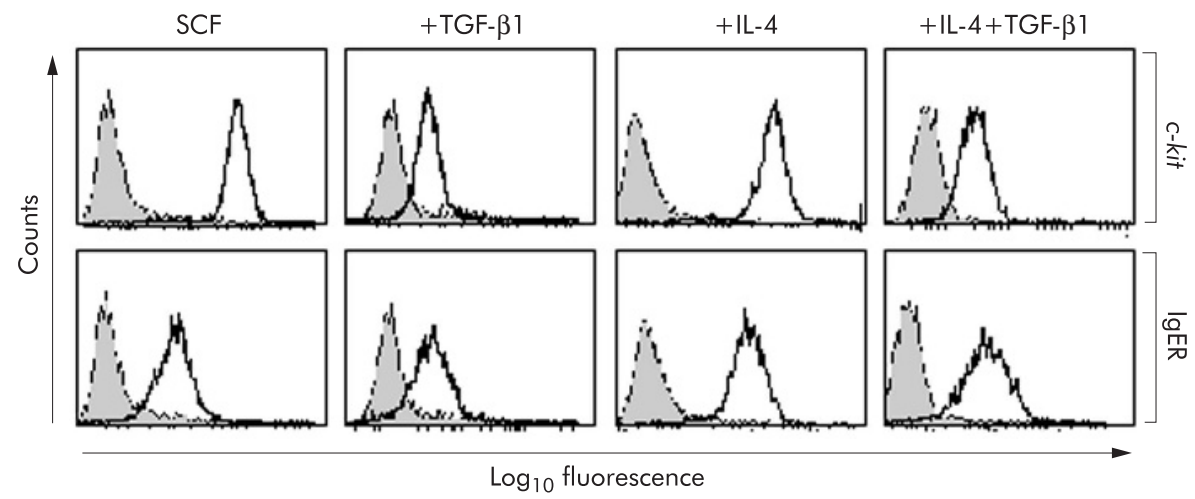

Figure 6 Transforming growth factor $\beta 1$ (TGF- $\beta 1$ ) reduced surface $c$-kit and high affinity lgE receptor (IgER) $\alpha$ chain expression in cultured human intestinal mast cells (MC). MC were cultured for 14 days in medium supplemented with cytokines, as indicated (same concentrations as in fig 2), and analysed for expression of stem cell factor (SCF) receptor c-kit and $\operatorname{lgER} \alpha$ chain. Grey areas represent matched isotype control stainings. One of three representative experiments is shown. IL-4, interleukin 4.

\section{TGF- $\beta 1$ promotes expression of COX-1 and COX- 2 in} human intestinal $M C$

To study the mechanism of TGF- $\beta 1$ induced enhancement of PGD2 production in MC triggered by IgER crosslinking, we analysed expression of key enzymes regulating PGD2 synthesis by semiquantitative RT-PCR and western blot analysis. We detected mRNAs encoding for CPLA2, COX-1, COX-2, and
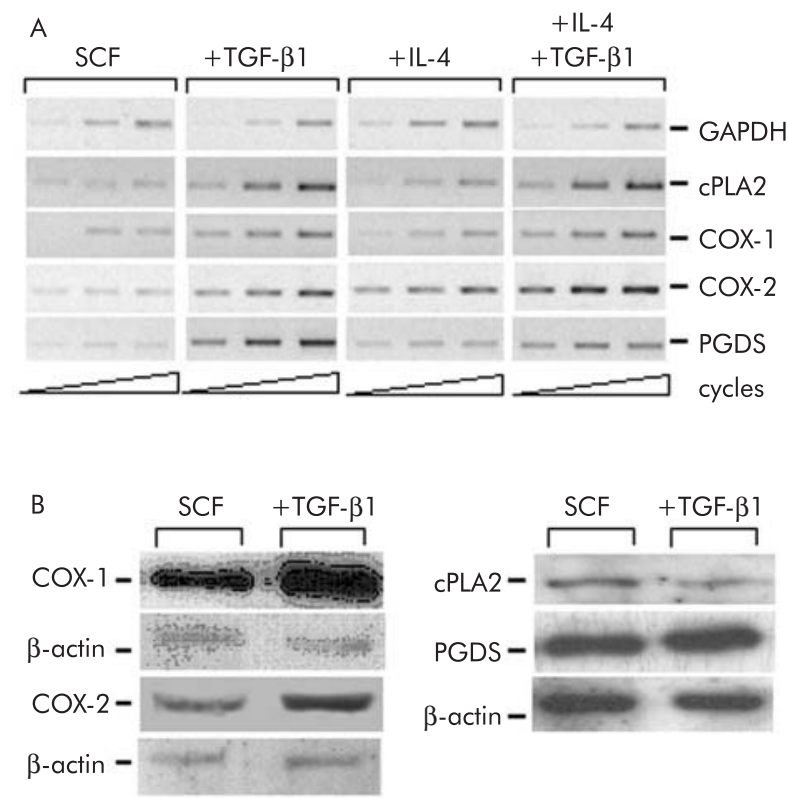

Figure 7 Expression of enzymes involved in prostaglandin D2 (PGD2) synthesis in mast cells (MC). Purified human intestinal MCs (purity $>98 \%$ ) were preincubated with stem cell factor (SCF), transforming growth factor $\beta 1$ (TGF- $\beta 1$ ), or interleukin 4 (IL-4) for 14-21 days (cytokine concentrations as in fig 2), washed, and challenged with mAb29C6 for 90 minutes to induce high affinity lgE receptor (IgER) crosslinking. (A) Semiquantitative reverse transcriptase-polymerase chain reaction for analysis of mRNAs encoding for GAPDH (452 bp; 23, 25 , and 27 polymerase chain reaction cycles), cytosolic phospholipase A2 (cPLA2) (580 bp; 33, 35, and 37 cycles), cyclooxygenase 1 (COX-1) (303 bp; 31, 33, and 35 cycles), COX-2 (305 bp; 31, 33, and 35 cycles), and haematopoietic prostaglandin synthase (PGDS) (342 bp; 31,33 , and 35 cycles). (B) Protein expression of COX-1 (72 kDa), COX2 (70 kDa), cPLA2 (105 kDa), PGDS (25 kDa), and actin (43 kDa) in MC analysed by western blot. The actin bands in the left column appear much weaker than in the right because these membranes were stripped following detection of the COX proteins and probed again for actin. In $(A)$ and $(B)$, one of three representative experiments is shown.
PGDS in MC cultured for 14 days in the presence of SCF (data not shown). IgER crosslinking induced by mAb29C6 for 90 minutes caused upregulation of COX-2 mRNA whereas mRNAs encoding for other enzymes remained unchanged (data not shown). Consistent with PGD2 release data, the presence ofTGF- $\beta 1$ during MC culture enhanced expression of all four enzymes known to regulate PGD2 synthesis in activated MC (fig 7A). For COX-1 and COX-2, mRNA data were confirmed at the protein level by western blot (fig 7B) but the amounts of cPLA2 and PGDS proteins were not altered by TGF- $\beta 1$.

\section{DISCUSSION}

In the present study, we have provided for the first time evidence that TGF- $\beta 1$ controls human intestinal MC functions. Our data show that in the presence of TGF- $\beta 1, \mathrm{MC}$ growth is retarded, and the profile of mediators released from MC triggered by IgER crosslinking is modulated. Interestingly, we found that many classical MC mediators, such as histamine, cys-LTs, and TNF- $\alpha$, thought to be responsible for the proinflammatory effects of $\mathrm{MC}$, were released to a lesser extent in the presence of TGF- $\beta 1$, while only one mediator, PGD2, was upregulated following stimulation of MC by IgER crosslinking. The observation that TGF- $\beta 1$ suppresses human intestinal MC functions in vitro agrees with previous reports indicating that TGF- $\beta 1$ is a unique anti-inflammatory cytokine constitutively expressed in the intestine, ${ }^{1}$ most likely to maintain ongoing inflammatory reactions triggered by bacteria and other luminal antigens at low levels. This concept was supported by the finding that deletion of TGF- $\beta 1$ and TGF-RII genes caused severe colitis, in which MC, as well as many other cells, may be involved. ${ }^{67}$ Obviously, TGF- $\beta 1$ controls the mucosal immune system not only by inducing IgA production and generating $\mathrm{T}_{\mathrm{H}} 3$ regulatory cells but also by controlling inflammatory effector cells such as macrophages, ${ }^{2}{ }^{3}$ eosinophils, ${ }^{4}$ and MC, as shown here, which were all found in the normal lamina propria of the human intestine.

Previous reports on the effects of TGF- $\beta 1$ in MC were mostly restricted to the murine system. ${ }^{19-24}$ Such data cannot be transferred easily to the human system because of the well documented heterogeneity of MC derived from different species and body sites. ${ }^{10}$ Moreover, most studies only examined TGF- $\beta 1$ effects on MC proliferation, not on mediator release, the main effector function of MC. Here, we have extended these data by demonstrating that the recovery rate of tissue derived human MC was strongly reduced in the presence of TGF- $\beta 1$. The growth inhibitory 
effect of TGF- $\beta 1$ was accompanied by both a reduction in MC proliferation and enhancement of MC apoptosis, and appeared in a concentration range similar to TGF- $\beta 1$ levels found in human plasma. ${ }^{31}$ Such TGF- $\beta$ l effects have been reported previously for epithelial, endothelial, and haematopoietic cells, including eosinophils and murine MC, in all of which TGF- $\beta 1$ causes cell cycle arrest.. ${ }^{22}$ Induction of apoptosis by TGF- $\beta 1$ was also found in human lymphoma cell lines, leukaemia cells, and normal blood eosinophils..$^{3-5}$ The mechanism of MC growth inhibition by TGF- $\beta 1$ is not clear. ${ }^{19}{ }^{20}$ According to our data, it is likely that TGF- $\beta 1$ exerts its effect on human intestinal MC to a large extent by downregulating $c$-kit, the receptor for SCF, the unique mast cell growth factor in rodents and humans. ${ }^{10}{ }^{11}$ Finally, our data agree with the clinical observation that some mastocytosis patients have TGF-RI negative MC, a condition that has been associated with a poorer prognosis compared with those having TGF-RI positive MC. ${ }^{32}$

Previous studies on the effect of TGF- $\beta 1$ on mediator release yielded conflicting results. It was reported that TGF- $\beta 1$ did not affect histamine, beta-hexosaminidase, or cys-LT release following IgE dependent activation, ${ }^{21}{ }^{22}$ that it inhibited antigen induced release of histamine and TNF- $\alpha$ dependent cytotoxicity, ${ }^{23}$ or that it even enhanced IgE dependent cys-LT production without affecting beta-hexosaminidase release in murine MC. ${ }^{24}$ Here, we investigated for the first time the effects of TGF- $\beta 1$ on mediator release in mature human MC. We found that TGF- $\beta 1$ switches the normal MC response to IgER crosslinking from unselective release of many inflammatory mediators to selective release of PGD2. MC releasing preferentially PGD2 has not been reported previously, and may contribute to the known immunomodulatory effects of TGF- $\beta 1$ as PGD2 is the ligand of the recently discovered receptor CRTH2 which selectively induces chemotaxis in $\mathrm{T}_{\mathrm{H}} 2$ cells, basophils, and eosinophils. ${ }^{33}$

To address possible mechanisms causing selective upregulation of PGD2 production in activated MC pretreated with TGF- $\beta 1$, we studied expression of IgER $\alpha$ chain and key enzymes known to be involved in PGD2 synthesis. We found slight downregulation of IgER $\alpha$ chain expression following culture with TGF- $\beta 1$ that might contribute to the fact that release of mediators such as histamine, cys-LT, and TNF- $\alpha$ was reduced by TGF- $\beta 1$. The TGF- $\beta 1$ induced increase in PGD2 production in MC activated by IgER crosslinking seems to be directly related to enhanced expression of COX-1 and 2 mRNA and protein following TGF- $\beta 1$ pretreatment of MC. cPLA2 and PGDS may also contribute to TGF- $\beta 1$ dependent enhancement of PGD2 production as mRNAs encoding for these enzymes were enhanced in MC challenged with TGF- $\beta 1$ although protein levels remained unchanged within an observation period of 90 minutes. Such a time period may be too short and, therefore, does not exclude the possibility that increased CPLA2 and PGDS protein levels occur at later time points (for example, following repetitive stimulation of MC for hours to days).

Interestingly, TGF- $\beta 1$ not only affected growth, survival, and mediator release but also the phenotype of MC. Addition of TGF- $\beta 1$ to human MC cultures enhanced the percentage of MC expressing both tryptase and chymase $\left(\mathrm{MC}_{\mathrm{TC}}\right)$. This MC subtype, also named "connective tissue-type $\mathrm{MC}^{\text {", is found }}$ mainly in the skin and intestinal submucosa. In contrast, MC expressing tryptase but no chymase $\left(\mathrm{MC}_{\mathrm{T}}\right)$, named "mucosatype $\mathrm{MC}^{\prime \prime}$, that predominate in the lung and intestinal mucosa, ${ }^{10}{ }^{30}$ were reduced by TGF- $\beta 1$. Presumably, TGF- $\beta 1$ induced chymase expression rather than selective apoptosis in $\mathrm{MC}_{\mathrm{T}}$ because it was shown that TGF- $\beta 1$ induced de novo expression of mouse MC protease 1 , a chymase-like protease, in developing murine bone marrow derived MC. ${ }^{34}$ Such findings strongly suggest that mature human tissue MC maintain the capacity to change their phenotype depending on exogenous factors such as TGF- $\beta 1$ or IL-4, which have opposite effects in this respect. Consistent with our in vitro findings, MC that accumulate in TGF- $\beta 1$ rich environments, such as intestinal strictures, predominantly belong to the $\mathrm{MC}_{\mathrm{TC}}$ subtype. ${ }^{11}{ }^{13}$ Finally, the profile of mediators we observed after culture of $\mathrm{MC}$ in the presence of TGF- $\beta 1$ may reflect alteration of the $\mathrm{MC}_{\mathrm{T}} / \mathrm{MC}_{\mathrm{TC}}$ ratio in our $\mathrm{MC}$ populations.

Our data might have several clinical implications as TGF- $\beta 1$ seems to be a unique regulator of the responsiveness of inflammatory cells such as MC towards different triggering agents. Proinflammatory stimuli such as lipopolysaccharide, TNF- $\alpha$, and IL- $1 \beta$, which are released during bacterial infection, were found to upregulate expression of Smad7, an intracellular protein inhibiting TGF- $\beta 1$ signalling. ${ }^{35}$ This in turn may facilitate activation of MC and other inflammatory cells required to initiate an innate immune response. In previous in vivo experiments, it has been clearly shown that MC activation is necessary for host defence against bacterial infections because their mediators, including TNF- $\alpha$, allow the recruitment of neutrophils needed for bacterial clearance at sites of infection. ${ }^{36}$ In the absence of inflammatory signals, TGF- $\beta 1$, apart from its effects on the specific immune response, may limit innate immune responses unless they are required. This hypothesis would imply that breakdown of the TGF- $\beta 1$ pathway leads to uncontrolled inflammation. Indeed, Monteleone et al reported such a condition recently by showing that Smad7 is upregulated in inflammatory bowel disease. ${ }^{37}$ Whereas reduced levels of TGF- $\beta 1$ or impaired TGF- $\beta 1$ signalling may lead to uncontrolled inflammation, conditions with normal TGF- $\beta 1$ levels are likely characterised by a controlled tissue MC number and activity, and by support of a " $\mathrm{T}_{\mathrm{H}} 2$ milieu" caused by preferential release of PGD2 in MC following activation. In contrast, enhanced TGF- $\beta 1$ levels may occur during chronic inflammation, possibly in the sense of some form of negative feedback mechanism, paralleled by ongoing tissue repair processes. This may contribute to fibrotic tissue transformation typically occurring in the course of chronic inflammation (for example, in Crohn's disease, where bowel fibrosis and strictures cause serious clinical problems). Clearly, further studies are necessary to confirm the pathophysiological role of impaired TGF- $\beta 1$ activity at mucosal sites.

\section{ACKNOWLEDGEMENTS}

The authors thank Gisela Weier and Nicole Steegmann for excellent technical assistance.

This work was supported by the Deutsche Forschungsgemeinschaft (SFB621-A8 to SCB).

\section{Authors' affiliations}

T Gebhardt, A Lorentz, F Detmer, C Trautwein, M P Manns, Department of Gastroenterology, Hepatology, and Endocrinology, Medical School of Hannover, D-30623 Hannover, Germany

H Bektas, Department of Abdominal and Transplant Surgery, Medical School of Hannover, D-30623 Hannover, Germany

S C Bischoff, Department of Clinical Nutrition and Prevention (140b), University of Hohenheim, D-70593 Stuttgart, Germany

Conflict of interest: None declared.

\section{REFERENCES}

1 Babyatsky MW, Rossiter G, Podolsky DK. Expression of transforming growth factors alpha and beta in colonic mucosa in inflammatory bowel disease. Gastroenterology 1996;1 10:975-84.

2 Letterio JJ, Roberts AB. Regulation of immune responses by TGF-beta. Annu Rev Immunol 1998;16:137-61.

3 Fortunel NO, Hatzfeld A, Hatzfeld JA. Transforming growth factor-beta: pleiotropic role in the regulation of hematopoiesis. Blood 2000;96:2022-36. 
4 Alam R, Forsythe P, Stafford S, et al. Transforming growth factor beta abrogates the effects of hematopoietins on eosinophils and induces their apoptosis. J Exp Med 1994;179:1041-5.

5 Blobe GC, Schiemann WP, Lodish HF. Role of transforming growth factor beta in human disease. N Engl J Med 2000;342:1350-8.

6 Shull MM, Ormsby I, Kier AB, et al. Targeted disruption of the mouse transforming growth factor-beta 1 gene results in multifocal inflammatory disease. Nature 1992;359:693-9.

7 Leveen $\mathrm{P}$, Larsson J, Ehinger $M$, et al. Induced disruption of the transforming growth factor beta type II receptor gene in mice causes a lethal inflammatory disorder that is transplantable. Blood 2002;100:560-8.

8 Sanderson N, Factor V, Nagy P, et al. Hepatic expression of mature transforming growth factor beta 1 in transgenic mice results in multiple tissue lesions. Proc Natl Acad Sci U S A 1995:92:2572-6.

9 Sime PJ, Xing Z, Graham FL, et al. Adenovector-mediated gene transfer of active transforming growth factor-betal induces prolonged severe fibrosis in rat lung. J Clin Invest 1997;100:768-76.

10 Metcalfe DD, Baram D, Mekori YA. Mast cells. Physiol Rev 1997:77:1033-79

11 Bischoff SC. Regulation and function of human intestinal mast cells. In: Marone G, Lichtenstein LM, Galli SJ, eds. Mast cells and basophils. New York: Academic Press, 2000:541-66.

12 Barbara G, Stanghellini V, De Giorgio R, et al. Activated mast cells in proximity to colonic nerves correlate with abdominal pain in irritable bowel syndrome. Gastroenterology 2004;126:693-702.

13 Gelbmann CM, Mestermann S, Gross V, et al. Strictures in Crohn's disease are characterised by an accumulation of mast cells colocalised with laminin but not with fibronectin or vitronectin. Gut 1999:45:210-17.

14 Rottem M, Hull G, Metcalfe DD. Demonstration of differential effects of cytokines on mast cells derived from murine bone marrow and peripheral blood mononuclear cells. Exp Hematol 1994;22:1147-55.

15 Bischoff SC, Schwengberg S, Raab R, et al. Functional properties of human intestinal mast cells cultured in a new culture system: enhancement of lgE receptor-dependent mediator release and response to stem cell factor. receptor-dependent mediator r

16 Bischoff SC, Sellge G, Lorentz A, et al. IL-4 enhances proliferation and mediator release in mature human mast cells. Proc Natl Acad Sci U S A 1999:96:8080-5.

17 Ochi H, Hirani WM, Yuan Q, et al. T helper cell type 2 cytokine-mediated comitogenic responses and CCR3 expression during differentiation of human mast cells in vitro. J Exp Med 1999;190:267-80

18 Gebhardt T, Sellge G, Lorentz A, et al. Cultured human intestinal mast cells express functional IL-3 receptors and respond to IL-3 by enhancing growth and $\mathrm{lgE}$ receptor-dependent mediator release. Eur J Immunol 2002;32:2308-16.

19 Mekori YA, Metcalfe DD. Transforming growth factor-beta prevents stem cell factor-mediated rescue of mast cells from apoptosis after IL-3 deprivation. J Immunol 1994; 153:2194-203.

20 Dubois CM, Ruscetti FW, Stankova J, et al. Transforming growth factor-beta regulates c-kit message stability and cell-surface protein expression in hematopoietic progenitors. Blood 1994;83:3138-45.

21 Broide DH, Wasserman SI, Alvaro-Gracia J, et al. Transforming growth factor-beta 1 selectively inhibits IL-3-dependent mast cell proliferation without affecting mast cell function or differentiation. J Immunol 1989;143:1591-7.
22 Toyota N, Hashimoto Y, Matsuo S, et al. Transforming growth factor beta 1 inhibits IL-3- and IL-4-dependent mouse connective tissue-type mast cell proliferation. Arch Dermatol Res 1995;287:198-201.

23 Bissonnette EY, Enciso JA, Befus AD. TGF-betal inhibits the release of histamine and tumor necrosis factor-alpha from mast cells through an autocrine pathway. Am J Respir Cell Mol Biol 1997;16:275-82.

24 Sanchez Mejia RO, Lam BK, Arm JP. Matrix-associated transforming growth factor-betal primes mouse bone marrow-derived mast cells for increased high-affinity Fc receptor for immunoglobulin E-dependent eicosanoid biosynthesis. Am J Respir Cell Mol Biol 2000;22:557-65.

25 Olsson N, Ulfgren AK, Nilsson G. Demonstration of mast cell chemotactic activity in synovial fluid from rheumatoid patients. Ann Rheum Dis 2001;60:187-93.

26 Zhang $\mathrm{H}$, Shaw AR, Mak A, et al. Endoglin is a component of the transforming growth factor (TGF)-beta receptor complex of human pre-B leukemic cells. J Immunol 1996; 156:564-73.

27 Zaitsu M, Hamasaki Y, Matsuo $M$, et al. New induction of leukotriene $A(4)$ hydrolase by interleukin- 4 and interleukin-13 in human polymorphonuclear leukocytes. Blood 2000;96:601-9.

28 Fernandez-Morata JC, Mullol J, Fuentes M, et al. Regulation of cyclooxygenase- 1 and -2 expression in human nasal mucosa. Effects of cytokines and dexamethasone. Clin Exp Allergy 2000;30:1275-84.

29 Yamashima T, Sakuda K, Tohma Y, et al. Prostaglandin D synthase (betatrace) in human arachnoid and meningioma cells: roles as a cell marker or in cerebrospinal fluid absorption, tumorigenesis, and calcification process. J Neurosci 1997; 17:2376-82.

30 Irani AA, Schechter NM, Craig SS, et al. Two types of human mast cells that have distinct neutral protease compositions. Proc Natl Acad Sci U S A 1986:83:4464-8

31 Junker U, Knoefel B, Nuske K, et al. Transforming growth factor beta 1 is significantly elevated in plasma of patients suffering from renal cell carcinoma. Cytokine 1996;8:794-8

32 Li CY, Baek JY. Mastocytosis and fibrosis: role of cytokines. Int Arch Allergy Immunol 2002;127:123-6.

33 Hirai H, Tanaka K, Yoshie O, et al. Prostaglandin D2 selectively induces chemotaxis in Thelper type 2 cells, eosinophils, and basophils via seventransmembrane receptor CRTH2. J Exp Med 2001;193:255-61.

34 Miller HR, Wright SH, Knight PA, et al. A novel function for transforming growth factor-betal: upregulation of the expression and the lgE-independent extracellular release of a mucosal mast cell granule-specific beta-chymase, mouse mast cell protease-1. Blood 1999;93:3473-86.

35 Bitzer M, von Gersdorff $G$, Liang $D$, et al. A mechanism of suppression of TGF-beta/SMAD signaling by NF-kappa B/RelA. Genes Dev 2000; 14:187-97.

36 Malaviya R, Ikeda T, Ross E, et al. Mast cell modulation of neutrophil influx and bacterial clearance at sites of infection through TNF-alpha. Nature 1996;381:77-80.

37 Monteleone G, Kumberova A, Croft NM, et al. Blocking Smad7 restores TGFbetal signaling in chronic inflammatory bowel disease. J Clin Invest 2001; 108:601-9.

38 Monteleone G, Mann J, Monteleone I, et al. A failure of transforming growth factor-betal negative regulation maintains sustained NF-kappaB activation in gut inflammation. J Biol Chem 2004;279:3925-32. 